Available online on 15.04.2020 at http://ajprd.com

Available online on 15.04.2020 at http://ajprd.com
Open Access to Pharmaceutical and Medical Research

Open $\odot$ Access

Mini Review

\title{
Ayurvedic Life Style Drugs Promise Blissful Life
}

\author{
Mayank Dimri, Luv Kush
}

SBS University Balawala, Dehradun-248161 (Uttarakhand), India

\section{A B S T R A C T}

Holistic health concept of ayurveda formulated polyactive pharmacons of life style drugs for regenerating the natural Physiological order. They eradicate disorders caused by addictive and subjective life styles of poor quality.

Keywords: Ayurveda, Life style drugs, Polyhebral formulation, Tridosa

A R T I C L E I N F O: Received 10 Jan. 2020; Review Completed 06 March 2020; Accepted 28 March 2020 ; Available online 15 April. 2020

Cite this article as:

Dimri M, Kush L, Ayurvedic Life Style Drugs Promise Blissful Life, Asian Journal of Pharmaceutical Research and

Development. 2020; 8(2):88-89. DOI: http://dx.doi.org/10.22270/ajprd.v8i2.668

*Address for Correspondence:

Luv Kush, SBS University Balawala, Dehradun-248161 (Uttarakhand), India

\section{INTRODUCTION}

A yurveda means 'Science of Life', derived from the ancient vedic culture ${ }^{1}$. It represents the complimentary/ alternative medical system. Conceptually ayurveda deals with tridosa in which the equilibrium/ balance of Vata, Pitta and Kapha are disturbed.

Vata energy - is essential for the movement.

Pitta energy - is essential for the metabolic machinery.

Kapha energy - is essential for the structural integrity.

The conception endows constitution of human body which remains constant throughout the life. It includes the combination of physical, mental and emotional characteristics. The ayurvedic equilibrium of Vata, Pitta and Kapha sustains holistic balance of body, mind and conseiousness by promoting their togetherness. The cellular fluids and nutrients are the substrates of bioenergy and body dynamics. Ayurveda advocates herbal friendliness to maintain natural order of the human body.

\section{THEORETICAL METHODOLOGY}

It is very unusual that 23 definitions of life style drugs ${ }^{2-7}$ in the scientific literature are cited. We attempted to give a comprehensive definition, based on our deliberations of ideal qualifications of life style drugs. They are :

- It should improve quality of life

- It should maintain the pleasure threshold for the creativity.
- It imparts facial charm and attraction for social esteem.

- It retrogrades aging with rebirth of youthfulness.

- It gets rid of unhappiness caused by apprehension, stress, depression and phobias.

All these criterions allowed us to renovate the definition of life style drug. Therapeutically effectiveness of life style drug can be defined as it alleviates erratic life style syndromes, renders - love, hope, peace and grace to life for healthy longevity. The ayurvedic life style embraces right thinking, diet and use of herbs. We believe that life style of an individual has two types of activities.

Extrovert - Interaction with external environment, which requires physical strength, stamina and endurance. Here social profiles determine life style and their disorders.

Introvert - Interaction with self- introspection. This needs emotional and spiritual strengths for creativity.

We selected the five ayurvedic formulations of life style drugs for this study ${ }^{8}$,

1. Arjuna

2. Dhootapapeshwar brahmi vati buddhivardhak

3. Himalaya Triphala tablets

4. Life capsules

5. Stay on capsule

\section{DISCUSSION AND RESULT}

The polyherbal formulations have traditional ingredients of natural products ${ }^{9}$ like amla, shilajit, kesar, ashwagandha, 
bharmi, shankpuspi, giloy, musli, kauch, haritaki,and bibitaki. Possibily their functional doses incoporated in formulations by rasayan technique are well suited for matching the western medications. It appears that structural alerts of toxicophoric functionalities are at minimal levels. Moreover such formulations comply with Ayurvedicophoric ${ }^{10,11}$ character suggested by Luv Kush et al.

The life style drugs are suppposed to improve the quality if life. It depends on essential life promoting bioactivities of phytochemicals present the ethical formulations. They are listed here ${ }^{9}$ :

Adaptogenic (anti-stress), Anti-ageing, Antianxity, Antidegenerative, Anti-inflammatory, Anti-mutagenic, Antioxidantive Rasayana also imparts additional protective and modulatory actions for healthy survival of human life. They are immuno-modulatory or immuno-potentiating, cardioprotective, nuroprotective and hepatoprotective. The ayurvedic formulations of life style drugs are well gifted by all these activities therefore they are rejuvenating and restortive tonics. We also suggest that ethical formulations must be microbiome protective and maintain GIT health at best functional level. The ayurvedic formulations of life style drugs8 belong to our ancient medical heritage so they promote ethics of complimentary medicine in integrative manner.

\section{CONCLUSION}

We have pioneered the new definition of an ideal ayurvedic life style drugs, supported by basic human biology where physiological order of metabolic equilibrium is sustained. We conclude that ayurvedic life style drugs re-establish health order.

\section{REFERENCES}

1. https://siddhalepa.com/index.php/concepts-of-ayurveda/

2. Rhaman, et al: Impact of Lifestyle Drugs on Socity, 2010.

3. Burger Medicinal Chemistry and Drug Discovery, lifestyle and Over The Counter drugs, sixth edition, Volume 4, Khawala Abu lazza, Vihcent Li, Grahm Parr, Edited by Donald J, Abraham 2003.

4. http://en.Wikipedia.org/wiki/Lifestyledrugs

5. J.Weber, The New Era of Lifestyle Drugs,available online at http://www.businessweeek.com/1998/19/b35777001.htm, accessed on December 28,2001.

6. R.Herman, International Herald Tribune, November 18, 1998.pp21.

7. http://72.14.235.104/search?q==cache:woeVNpa6nSOJ:www.biom edcentral.com/content/pd/cd472259.pdf+defination+of+lifestyle+dr ugs\&en\&ct=cink\&cd7\&gl=in

8. https://www.google.com/search?q=ayurvedic+life+style+drugs\&tb $\mathrm{m}=$ isch\&ved=2ahUKEwiYrtjUmp_oAhWTHXIKHWxQAicQ2 cCegQIABAA.

9. A Selection of prime ayurvedic plants drugs, ancient-modern concordance, Sukh Dev, Anamaya publication, 2006.

10. Luv Kush et al ,Trichophoric Ayurvedicophore, IJIRD, vol 2 Issue 7,2013.

11. Akshay Negi, Hair Related Psychosocial Pharmaceuticals- Thesis 2007, submitted to Hemwati Nandan Bahuguna Garhwal University Srinagar(Garhwal), Uttarakhand. 